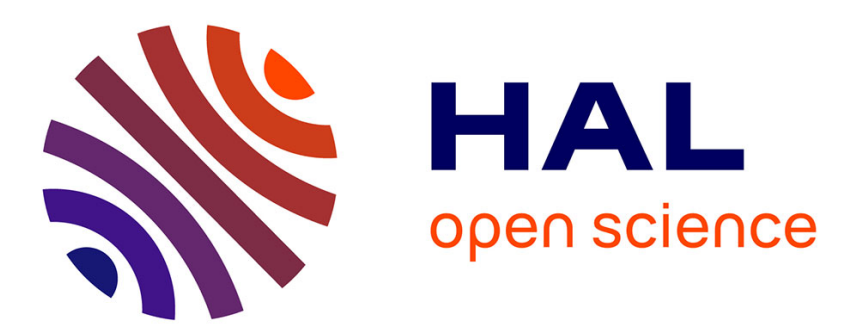

\title{
Numerical investigations of fault propagation and forced-fold using a non smooth discrete element method
}

\author{
Mathieu Renouf, Frédéric Dubois, Pierre Alart
}

\section{To cite this version:}

Mathieu Renouf, Frédéric Dubois, Pierre Alart. Numerical investigations of fault propagation and forced-fold using a non smooth discrete element method. Revue Européenne de Mécanique Numérique/European Journal of Computational Mechanics, 2006, 15 (5), pp.549-570. 10.3166/remn.15.549-570 . hal-00447273

\section{HAL Id: hal-00447273 \\ https://hal.science/hal-00447273}

Submitted on 11 Oct 2017

HAL is a multi-disciplinary open access archive for the deposit and dissemination of scientific research documents, whether they are published or not. The documents may come from teaching and research institutions in France or abroad, or from public or private research centers.
L'archive ouverte pluridisciplinaire HAL, est destinée au dépôt et à la diffusion de documents scientifiques de niveau recherche, publiés ou non, émanant des établissements d'enseignement et de recherche français ou étrangers, des laboratoires publics ou privés.

\section{(ㄷ)(1) $\$$}

Distributed under a Creative Commons Attribution - NonCommerciall 4.0 International 


\section{Numerical investigations of fault propagation and forced-fold using a non smooth discrete element method}

\section{Mathieu Renouf* — Frédéric Dubois ${ }^{* *}$ — Pierre Alart ${ }^{* *}$}

${ }^{*}$ LaMCoS - UMR 5514

INSA de Lyon - Bâtiment Jean d'Alembert

18-20 rue des sciences, F-69621 Villeurbanne cedex

Mathieu.Renouf@insa-lyon.fr

${ }^{* *} L M G C-U M R 5508$

Université Montpellier II - CC 048

Place Eugène Bataillon F-34095 Montpellier cedex 5

\{dubois,alart\}@lmgc.univ-montp2.fr

ABSTRACT. Geophysical problems as forced-fold evolution and fault propagation induce large deformations and many localisation. The continuum mechanics does not seem the more appropriate for their description and it appears more interesting to represent the media as initially discontinuous. To face both phenomena, a non smooth Discrete Element Method is used. Geophysical structures are considered as collection of rigid disks which interact by cohesive frictional contact laws. Numerical geophysical formations are correlated to mechanical properties of structures through observation and mechanical analysis.

RÉSUMÉ. Les problèmes géophysiques tels que l'évolution des plis et la propagation de failles induisent de grandes déformations et de nombreuses localisations. Il apparaît donc difficile de décrire le problème avec les outils de la mécanique des milieux continus, et il est donc préférable de représenter la structure comme initialement divisée. Ces deux phénomènes sont étudiés via une approche non régulière par éléments discrets. Les structures géologiques sont considérées comme des collections de particules dont les interactions répondent à des lois de contact cohésif frottant. Les observations des structures géophysiques numériques sont corrélées aux propriétés des structures au travers d'une analyse mécanique.

KEYWORDS: discrete element method, non smooth mechanics, granular material, fault, fold. MOTS-CLÉS : méthode par élements discrets, mécanique non régulière, granulats, failles, plis. 


\section{Introduction}

Many mechanical, tribological and geophysical problems bring difficulties such as large deformations, fracture, multiple localisations or wear. Numerical tools have been developed and adapted to fill the lack of knowledge and to bring informations in fields where experimental approaches are limited (for example, contact interface measures). If for some applications efficient numerical methods are well identified, there exist some problems where no well suited methods have been explicitly determined. It is the case of two geophysical phenomena: propagation fault and forced-fold evolution.

Using the continuum mechanics approach, the standard Finite Element Method (FEM) is not really appropriate to simulate this kind of phenomena. Kinematic and mechanical model used can only predict the zone of localisation and not represented its evolution especially when large deformations occur. It is clearly due to the continuous description of the model. Among the improvements of the standard method, the well known X-FEM (Belytschko et al., 2000) allows to describe localisation phenomena such as fracture but efficient re-meshing techniques must be used to follow fracture with accuracy and preserve CPU time. A solution could be found with mesh-less approaches such as the Natural Element Method (NEM) (Yvonnet et al., 2005) which appears as a good alternative to extended FEM, but as the previous one, it seems difficult to observe mixing which occurs in forced-fold evolution or surface movements created by the fault propagation such as avalanches.

Discrete Element Methods (DEM) which consider the media as fully discontinuous appear the well suited to describe these phenomena. When the continuum mechanics is not the more appropriate to describe the problem, it appears more interesting to represent the media as initially discontinuous and compute the evolution of each element. Moreover when the medium heterogeneity has a strong influence on its evolution (it is the case of the previous geophysical problems), it is important to deal with the discontinuous feature of the structure.

The aim of the paper is to present the adaptation of granular mechanical tools to the simulations of fault propagation and forced-folds through a mechanical analysis. These numerical investigations on geophysical phenomena are presented following the preliminary study presented in (Renouf, 2004). In the Section 2, the geophysical context and related numerical works are exposed. Different DEMs currently used in the simulation of granular material are exposed (contact formulation and time-integration scheme) in the Section 3. A focus on the held method and the interaction law used is presented in Section 4. In the Section 5 dedicated to geophysical applications, fold formation and fault propagation problems, are respectively studied in Subsection 5.2 and 5.3 and finally the Section 6 concludes the paper.

\section{Geophysical context}

Earth deformations are the result of motions of large continental plates. Their quasi-static motion produces mechanical solicitations such as traction, compression 
and shear. Combinations of theses solicitations lead at the earth time scale to the occurring of geophysical structures such as faults and folds. These structures present a dynamical character in regard of their time evolution. Their dramatic consequences on the human environment (Chang et al., 2005) motive a large number of studies to understand their mechanism and to prevent geophysical disasters.

Initial researches result first from in-situ and post-mortem observations of earth deformations. Consequently explanations about the history of structures lay on hypothesis which can be verified with difficulty. The direct consequence is the motivation of more accurate researches to understand and to reproduce the evolution of the structure. In this aim, experiments on analogue models (sandbox model) have been developed (Hubbert, 1951). It consists on the reproduction of the studied geophysical structure at the laboratory scale. Dry layers of sand are laid down a large box. Layers can have or not the same mechanical properties. Then external solicitations are applied on the structure (compaction, shear...). Although deformations similar to the ones observed in the crust can be reproduced with accuracy, analogue models are often limited in the range of problems that they can examine (granular internal friction coefficients for example (Lohrmann et al., 2003)).

Fault propagation and forced-folds have been modelled both kinematically (Hardy et al., 1999) and mechanically. In spite of the fact that the models provide some feasible behaviour, they have some limitations. On the one hand, the kinematic models use idealised velocity distributions with or without mechanical validity. On the other hand mechanical models suppose an idealistic rock behaviour and loading conditions during folding and do not model fault explicitly.

Some models use FEM for a greater flexibility (Cardozo et al., 2003; Exadaktylos et al., 2003) and consider a wider range of rheologies and boundary conditions. However, these methods have some difficulty in modelling large amounts of deformations accurately, especially the succession of faults observed in analogue models. Usually in geophysical applications, FEM models are built around a continuity assumption at some scale of the model that prevents the elements from separating and makes large amounts of strain localisation very difficult.

DEM models have been used to study fold or fault (Burbidge et al., 2002; Finch et al., 2003). Although DEM models take into account structure discontinuity, the ones used lead to crystalline structures and have few particles to observe with accuracy fold phenomena. The interest of these works is underlined by more recent investigations on geophysical problem. Different results presented in (Renouf, 2004) underline also the feasibility of the non smooth approach. In (Hardy et al., 2006) more complex investigations are performed on the influence of the angle of the propagation fault.

\section{Discrete Element Method}

Discrete Element Methods appear as the most appropriate tool to represent the evolution of a media considered as a collection of particles. Rigid multi-body systems 
in virtual reality (Renouf et al., 2005), third-body particle flows in rheology (Fillot et al., 2005) or granular material in soil mechanics or geophysics (Chang et al., 2005) refer to the same concept of particle systems. This diversity of application fields and related topics motive the permanent improvements of DEMs.

Their developments start with the pioneer works of Cundall who developed the Distinct Element Method (Cundall, 1971). Initially used to simulate rock systems, the method is extended to the simulation of granular media (Cundall et al., 1979). Contact interactions are described by compliant model related to an admissible numerical penetration. Then, improvements of the method are proposed by (Kishino, 1988) with the so-called Granular Element Method. An incremental formulation, an iterative process and a convergence criterion are added to respect the motion equation not always satisfied in the initial method. The GEM has been used for study different deformation modes in plasticity (Kishino et al., 2001).

An other contribution to DEMs is a variant of the Cundall approach, called Molecular Dynamics (MD) (Allen et al., 1987) which consists in simulating the dynamics of atom and molecule in order to deduce macroscopic properties of the matter. As Cundall method and GEM, MD resorts to compliant model to describe contact between particles. The motion equations are not always satisfied but the simulation time step is kept small enough to ensure integration scheme stability. Moreover, some numerical artefact can be added, such as numerical viscosity, to control the energy evolution in the system.

The Contact Dynamics method initially developed by (Moreau, 1988) based on the convex analysis framework appears as a different approach. Contrary to compliant models, no regularisation scheme is used to describe particle interactions: the non smooth contact feature is preserved according to an implicit formulation of the global contact problem solved classically using a projected block splitting algorithm. Further works lead to the extension of the method to multi-contact simulations of collections of deformable bodies (Jean, 1999) and the method becomes the so-called Non Smooth Contact Dynamics method (NSCD). Different strategies must be used to solve the implicit contact problem: the bi-potential method (de Saxcé et al., 1991), the Newton's method (Alart et al., 1991), the Conjugate Projected Gradient algorithm (Renouf et al., 2004), etc.

If the contact description appears often as the most important part of DEMs, contact detection and time integration are both two important phases in this scheme. If the contact detection is identical for all the DEMs, the time-integration scheme defers from a method to an other. In smooth DEM, since the contact regularisation requires small time step, second order schemes are adapted: the Gear method for MD (Allen et al., 1987), a Newmark scheme for Cundall' DEM and GEM or a Verlet scheme (Iordanoff et al., 2002). In non smooth DEM, especially when dense granular assemblies are considered, shocks can be occurred. It seems not appropriate to deal with the second time derivative of the configuration parameter, especially when large time step are used. A non smooth DEM may work with large time step and a first order scheme as Euler scheme or second order one as the theta-method is required. 
The Non Smooth Contact Dynamics approach is well adapted to simultaneous multi-contact problems occurring for instance in granular flows. It is quite different from the Event Driven (ED) techniques (Baraff, 1993; Pfeiffer et al., 1996) for which the impacts are isolated in time. After catching the impact time, high order scheme are used between two impacts to describe with more accuracy the evolution of particles.

Consequently, the comparison of the different numerical approaches has to account for the context of application to provide pertinent conclusions in agreement with experimental results (Lanier et al., 2000; Renouf et al., 2005; Renouf et al., 2005).

\section{Contact Dynamics framework}

\subsection{Local formulation}

The approach used in the present paper is based on the Contact Dynamic framework developed by (Moreau, 1988) and its extensions proposed by (Jean, 1999). The local variables, defined in the local frames, are preferred to the global ones: the local relative velocities $\mathbf{v}_{\alpha}$ ( $\alpha$, index of the contact number) are concatenated in a large vector $\mathbf{v}$, the local impulses $\mathbf{r}_{\alpha}$ in a vector $\mathbf{r}$. The corresponding global variables are the generalised velocities of the system (collection of bodies) $\dot{\mathbf{q}}$, first time derivative of the configuration parameter $\mathbf{q}$, and the contact forces $\mathbf{R}$ applied to all the bodies.

(a)

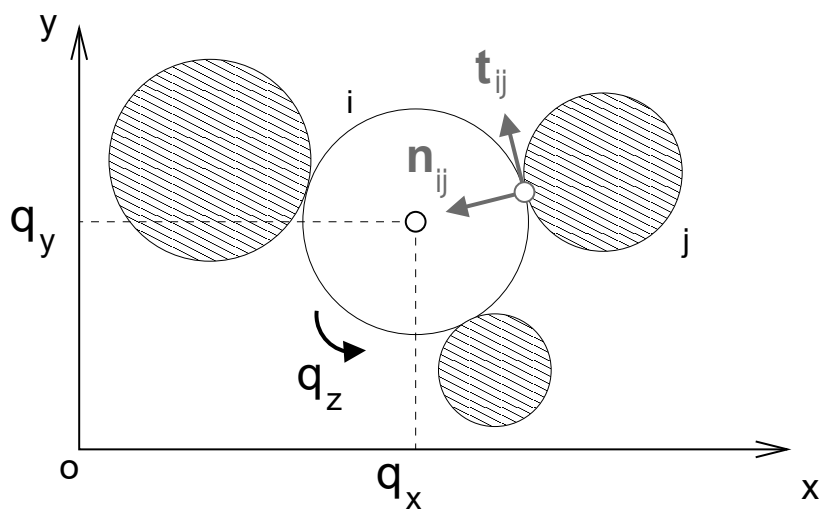

(b)

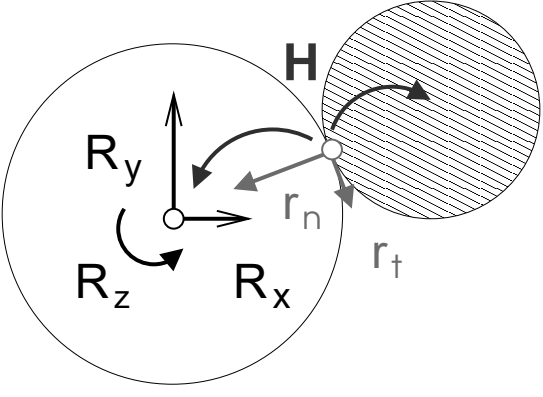

Figure 1. Representation of: (a) the global and local frames and (b) the linear mapping

Local variables are related to global ones via the linear mapping $\mathbb{H}$ which transfers informations computed at the contact points to bodies in contact. It can be summarised by the following system:

$$
\left\{\begin{array}{l}
\mathbf{R}=\mathbb{H} \mathbf{r} \\
\mathbf{v}=\mathbb{H}^{*} \dot{\mathbf{q}}
\end{array} .\right.
$$

where $\mathbb{H}^{*}$ is the transpose of $\mathbb{H}$. Then both mapping contain all local informations such as the local frame defined at each contact point. 


\subsection{Global formulation}

Since in multi-contact systems, shocks are expected, the velocity may be discontinuous and the acceleration can not be defined as the usual second time derivative of q. Consequently the classical equation of motion is reformulated in terms of differential measure equation:

$$
\mathbb{M} d \dot{\mathbf{q}}=\mathbf{F}^{e x t}(t, \mathbf{q}, \dot{\mathbf{q}}) d t+d \mathbf{R},
$$

where $\mathbb{M}$ represents the inertia matrix and $\mathbf{F}^{\text {ext }}$ the external forces. $d t$ is the Lebesgue measure on the real space $\mathbb{R}, d \dot{\mathbf{q}}$ is a differential measure representing the acceleration and $d \mathbf{R}$ is a differential measure of impulses. A $\theta$ integration scheme is used to discrete Equation [2]. Scheme stability condition implies that $\theta$ remains between $1 / 2$ and 1 . The $\theta$-method is an implicit scheme, equal to the backward Euler's one when $\theta=1$.

Proceeding to the time discretization, the contact problem is solved over the interval $\left.] t_{i}, t_{i+1}\right]$ of length $h$ in the terms previously defined. Then successive approximations of both Equation [2] and first time derivative of the configuration parameter lead to the following system:

$$
\left\{\begin{array}{l}
\dot{\mathbf{q}}_{i+1}=\dot{\mathbf{q}}_{i}^{\text {free }}+h\left(\mathbb{M}^{-1}\right) \mathbf{R}_{i+1} \\
\mathbf{q}_{i+1}=\mathbf{q}_{i}+h \theta \dot{\mathbf{q}}_{i+1}+h(1-\theta) \dot{\mathbf{q}}_{i}
\end{array}\right.
$$

with

$$
\dot{\mathbf{q}}_{i}^{\text {free }}=\dot{\mathbf{q}}_{i}+\mathbb{M}^{-1} h\left(\theta \mathbf{F}_{i+1}^{e x t}+(1-\theta) \mathbf{F}_{i}^{e x t}\right)
$$

where $\dot{\mathbf{q}}^{\text {free }}$ denotes the free velocity (velocity computed without contact forces). Quantities indexed by $i$ (resp. $i+1)$ refer to time $t_{i}$ (resp. $t_{i+1}$ ). For rigid body system, the inertia matrix $\mathbb{M}$ is diagonal and easily invertible, internal forces vanish and the external forces are given by a function of time. For deformable bodies, a linearising procedure via a Newton scheme, allows us to obtain the same set of discretised equations with account of the stiffness and damping matrices (Jean, 1999).

The second Equation of system [3] is used to update the system. When $\theta=1$ the contact detection is performed using the configuration parameter at time $t_{i}$. On the contrary, when $\theta \neq 1$, the contact detection is performed using a prediction of the configuration parameter (at time $t_{i}+h(1-\theta)$ ). In this case the $\theta$-method corresponds to the well-known predictor-corrector scheme.

Using the Equations [1] in the first Equation of system [3], the global discretization of the equation of motion and the contact laws can be summarised in the following system:

$$
\left\{\begin{array}{l}
\mathbb{W} h \mathbf{r}_{i+1}-\mathbf{v}_{i+1}=-\mathbf{v}_{\text {free }} \\
\text { ContactLaw }\left[\mathbf{v}_{i+1}, \mathbf{r}_{i+1}\right]
\end{array}\right.
$$

where $\mathbb{W}\left(=\mathbb{H}^{*} \mathbb{M}^{-1} \mathbb{H}\right)$ is the Delassus operator, which models the local behaviour of the solids at the contact points. The right-hand-side of the first Equation in [4] 
represents the free relative velocity only accounting for the internal and external forces $\mathbf{F}(t)$. The second Equation in [4] requires that the contact law must be satisfied by each component of the couple $\left(\mathbf{v}_{i+1}, \mathbf{r}_{i+1}\right)$. A specification of the general splitting method dedicated to contact problems is used to solve system [4], the so-called Block Non Smooth Gauss-Seidel algorithm (NSGS) a splitting method exposed in (Cottle et al., 1992). The global splitting scheme is written down as follows for the first Equation of system [3]:

$$
\begin{aligned}
\mathbb{W}_{\alpha \alpha} \mathbf{r}_{\alpha}^{k+1}-\mathbf{v}_{\alpha}^{k+1} & =-\mathbf{v}_{\alpha, f r e e}-\sum_{\beta<\alpha} \mathbb{W}_{\alpha \beta} \mathbf{r}_{\beta}^{k+1}-\sum_{\beta>\alpha} \mathbb{W}_{\alpha \beta} \mathbf{r}_{\beta}^{k} \\
& =\mathbf{b}_{\alpha}^{k}
\end{aligned}
$$

where the index $k$ refers to the splitting method iterations and $n_{c}$ the number of contacts. The time index is omitted to make pleasant reading. This solver has proved to be very robust and efficient on a large collection of heterogeneous problems (Jean et al., 2001; Saussine et al., 2006) and benefits of a parallel version (Renouf et al., 2004) to ensure reduced simulation time.

When the system [4] is solved, the contact forces are introduced in the first Equation of system [3] to compute the velocity at time $t_{i+1}$. Then this last one is introduced in the second Equation of system [3] to correct the configuration parameter.

Table 1. Pseudo code of the NSCD approach

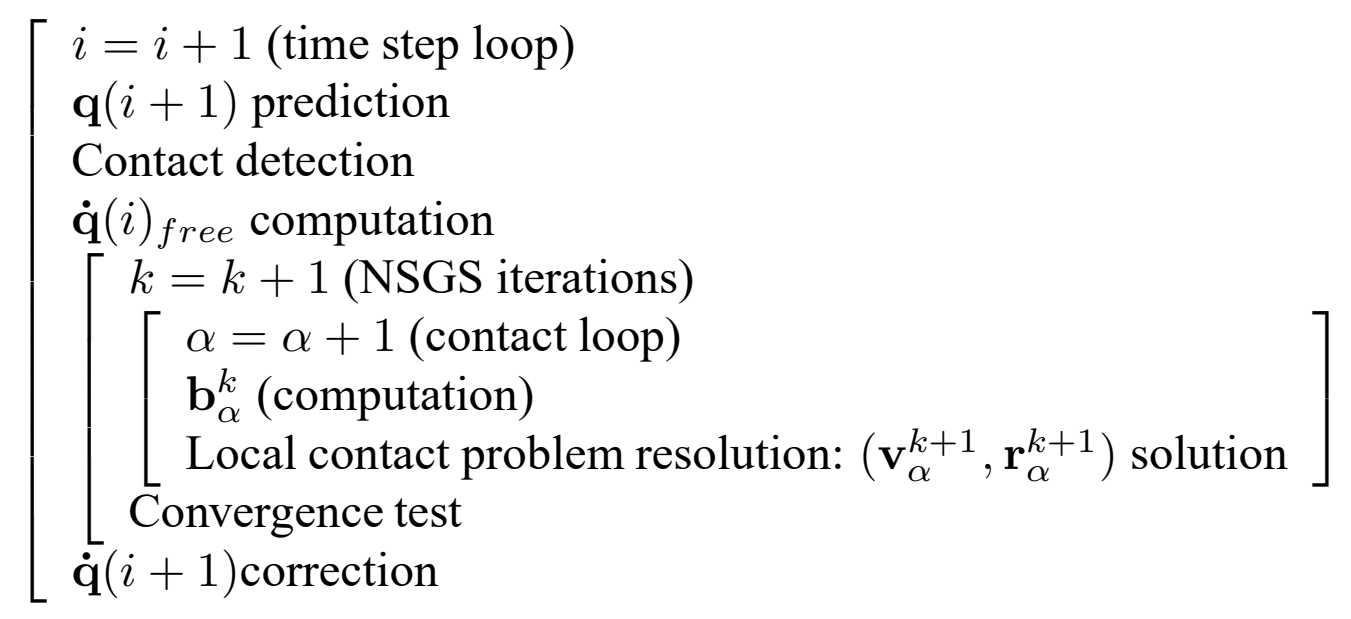

\subsection{Frictional and cohesive contact laws}

When collections of rigid bodies are considered, the physical behaviour of the system is deeply dependent on the interaction law between particles. As body deformation are not taken into account, it controls the evolution of the media. The contact law must be chosen according to the behaviour of the real media. 
Modelling complex phenomena which occur in geological formations (erosion, fracture, sedimentation) is out the scope of this paper. Nevertheless some rough interaction laws provide pertinent indications about geophysical phenomena. In the present paper, a frictional and a cohesive laws are used. The frictional contact law combines a velocity Signorini condition and the Coulomb friction law (Figure 2).
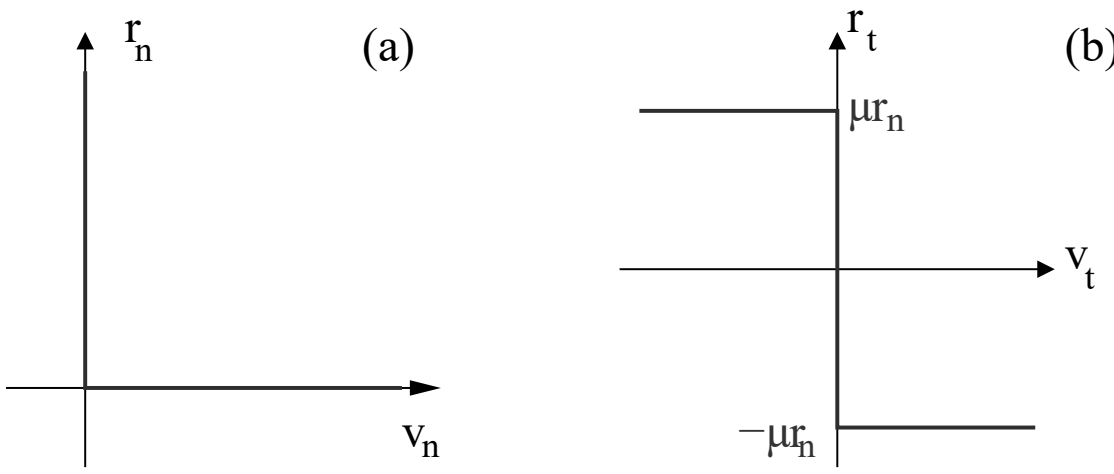

Figure 2. Graph of the velocity Signorini condition (a) and the Coulomb's friction (b)

Both graphs can be summarised by the following system of equation involving the normal and tangential components of the local unknowns:

$$
\left\{\begin{array}{l}
r_{n} \geq 0 \quad v_{n} \geq 0 \quad r_{n} \cdot v_{n}=0 \\
\text { If }\left\|r_{t}\right\|<\mu r_{n} \text { then } v_{t}=0 \\
\text { else } r_{t}=\epsilon \mu r_{n} \text { and } \epsilon v_{t}<0
\end{array}\right.
$$

where $\mu$ is the friction coefficient and $\epsilon$ takes the values $\{-1,+1\}$ according to the sliding direction.

The second law, the non smooth Lennard-Jones law (Figure 3a), corresponds to a simplification of phenomena present in a geophysical structure. It takes into account water effects and induces cohesion between particles.
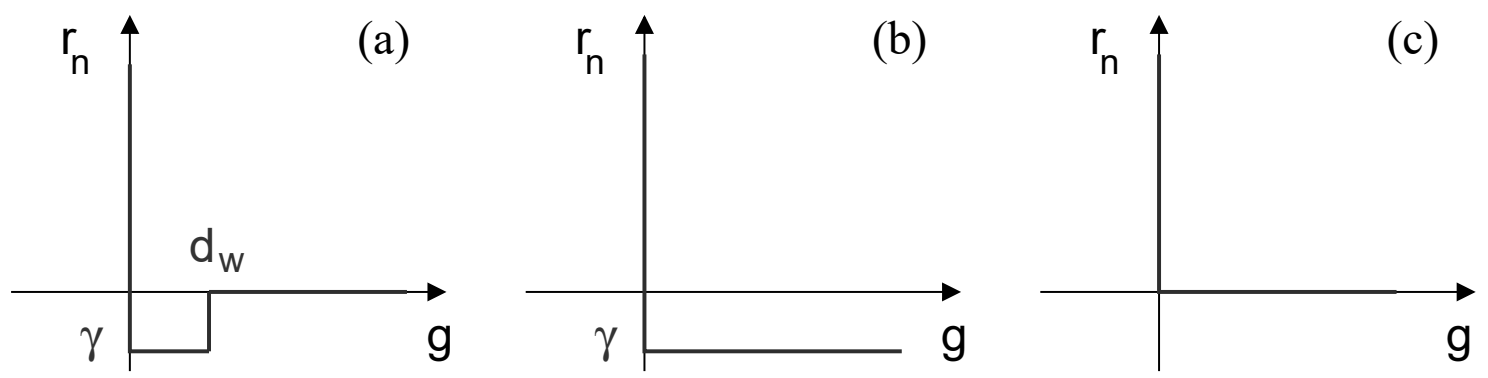

Figure 3. Graph of the non smooth Lennard-Jones law (a) as a combination of two Signorini graphs with (b) and without (c) a $\gamma$-translation along the $r_{n}$ axis. $\gamma$ represents the cohesive force while $g$ the distance between bodies

Two parameters are considered: a cohesive force $\gamma$ which represents a constant force in oposition of body detachment and the distance $d_{w}$ which defines the attraction 
area of each body. The graph of the non smooth Lennard-Jones law can be seen as a combination of two Signorini graphs according to the contact status (Figure $3 \mathrm{~b}$ and $3 c)$. If body attraction areas do not overlap then the contact status is non contact $\left(r_{n}=0\right.$ and $\left.g>d_{w}\right)$. If body attraction areas overlaps and the gap between bodies is not equal to zero, a additional cohesive force interferes then the contact status is cohesive $\left(\gamma<r_{n}<0\right.$ and $\left.g \leq d_{w}\right)$. Finaly the contact status is stick when the gap vanishes $\left(r_{n} \geq 0\right.$ and $\left.g \leq d_{w}\right)$. When $\gamma=0$ then $d_{w}=0$ and the cohesive status is no more considered. In this case the contact description is the classical Signorini condition. Note that the non contact condition appears as a condition of non attraction between the candidate and the antagonist bodies. If the System [4] is reduced to a single contact and if the cohesive contact law is used, one obtains the following system:

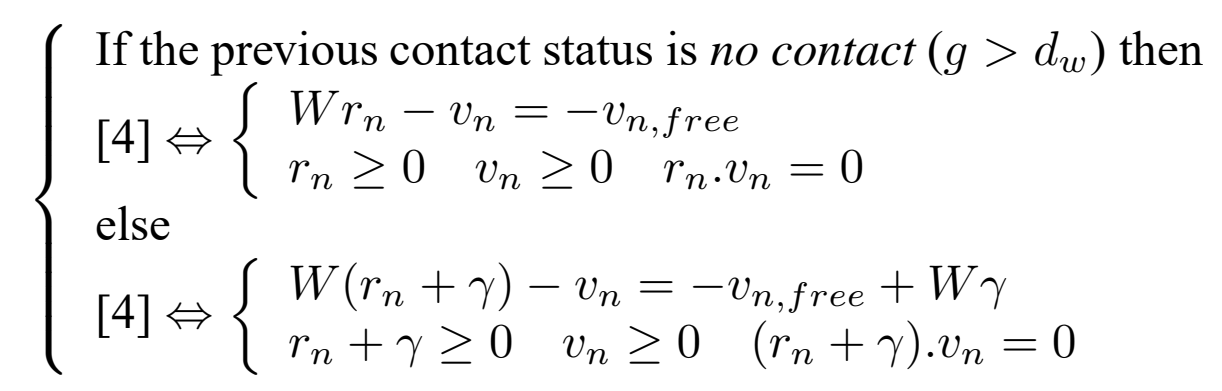

To close this section, it is important to underline that the aim is not to investigate several interaction models. Simple interaction laws are chosen, not so far of the real behaviour, defined by few additional parameters (here the friction $\mu$, the cohesion $\gamma$ and the wetting distance $d_{w}$ ) to ensure a higher control of the simulation process.

\section{Geophysical applications}

\subsection{Pre- and post-processing}

\subsubsection{Sample preparation}

In granular material, the history evolution plays an important role on the evolution of the media. Uniform bi-axial compression or compaction under gravity do not lead to the same sample properties. Consequently the preparation of samples and its initial state appear as an important part of the simulations. In the most cases they are themselves given by a simulation process. As it is difficult to predict how is the initial state of a geophysical formation, it has been obtained after a compact geometric deposit using the pre-processor developed by (Taboada et al., 2005). A state equilibrium is reached by a stabilisation phase under gravity forces. By this way no initial contact anisotropy is introduced in the media before the simulation. This process has been used both for the creation of fault propagation and forced-fold evolution samples. 


\subsubsection{Macroscopic quantities}

In granular material analysis is seems difficult to analyse the behaviour of each particle especially when the number is large. Macroscopic variables such as compacity or fabric tensor (Troadec et al., 2002) are very important to describe the media.

For a sub-domain $\Omega$ of a domain $\mathcal{E}$, for a collection of spherical rigid bodies, the stress tensor, denoted $\sigma$, is defined as:

$$
\sigma=\frac{1}{\operatorname{vol}(\Omega)} \sum_{\alpha \in \Omega} \mathbf{r}_{\alpha} \otimes \mathbf{l}_{\alpha}
$$

where $\mathbf{r}$ refers to the contact forces, $\mathbf{l}$ the inter-centre vector equal to $\left(r_{i}+r_{j}\right) \mathbf{n}$ for spherical shape ( $\mathbf{n}$ is the normal contact vector and $r_{i}$ and $r_{j}$ the respective radius of particles $i$ and $j$ involved in the contact). Using the stress tensor, the pressure and the deviatoric part are defined as:

$$
\left\{\begin{array}{l}
p=\frac{1}{2}\left(\sigma_{1}+\sigma_{2}\right) \\
q=\frac{1}{2}\left(\sigma_{1}-\sigma_{2}\right)
\end{array}\right.
$$

where $\sigma_{1}$ and $\sigma_{2}$ are the eigenvalues of $\sigma$. In the same way, the fabric tensor $\mathbf{f}$ is defined as:

$$
\mathbf{f}=\frac{1}{\operatorname{vol}(\Omega)} \sum_{\alpha \in \Omega} \mathbf{n}_{\alpha} \otimes \mathbf{n}_{\alpha}
$$

The anisotropy of $\Omega$ involves the eigenvalues of $\mathbf{f}, f_{1}$ and $f_{2}$, and is defined as:

$$
a=\frac{1}{2}\left(f_{1}-f_{2}\right)
$$

Contrary to the stress tensor it is difficult to define the strain tensor especially for system where large deformations and localisation are expected. Nevertheless, a notion of strain can be considered by tracking the evolution of some characteristic lengths in the sample. Here the dilatation in the two space direction is given by:

$$
\lambda_{*}\left(t_{i}\right)=\frac{\max \left(q_{*}\left(t_{i}\right)\right)-\min \left(q_{*}\left(t_{i}\right)\right)}{\max \left(q_{*}\left(t_{0}\right)\right)-\min \left(q_{*}\left(t_{0}\right)\right)}
$$

where $*$ is the $\mathrm{X}$ - or $\mathrm{Y}$ - component of the position of each particle.

\subsubsection{Trishear model}

The model has been introduced by Erslev (1991) to characterise fault evolution. The model decomposes the fault region in three parts as shown in the Figure 4.

Part I has a rigid body motion and its velocity is equal to the velocity of the fault. Part III does not move and its velocity field stays equal to zero. The hypothesis made on part II are: a constant volume $(\rho=c t e)$ which leads to $\operatorname{div}(\dot{\mathbf{q}})=0$, the velocity along the left side is constant and equal to the fault velocity, and the velocity along the 

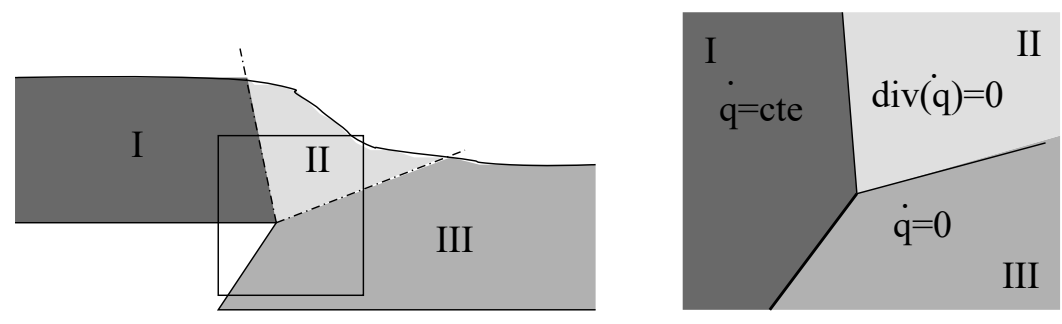

Figure 4. Tri-shear model: geometric decomposition of the fault. Part I has a rigid body motion (the velocity is equal to the velocity of the fault), part III does not move and part II satisfies continuity conditions on both boundaries

right side vanishes. The initial hypothesis can be extended, see for example (Hardy et al., 1999). This model is relevant for the first step of the evolution of a fault and thus can be used in finite element approach (Cardozo et al., 2003). The granular simulations can permit to determine what assumptions stay valid when large deformations occur.

\subsection{Forced-fold evolution}

\subsubsection{Simulation parameter}

The sample used for the forced-fold simulation is composed of 43000 hard cylinders. Their radius range from 0.42 to $0.56 \mathrm{~m}$. Their density is equal to $2800 \mathrm{~kg} . \mathrm{m}^{-3}$. The characteristic lengths (in meter) of the sample presented in the Figure 5a are: $L=1000, D=300, d=75, H=80$ and $h=30$.

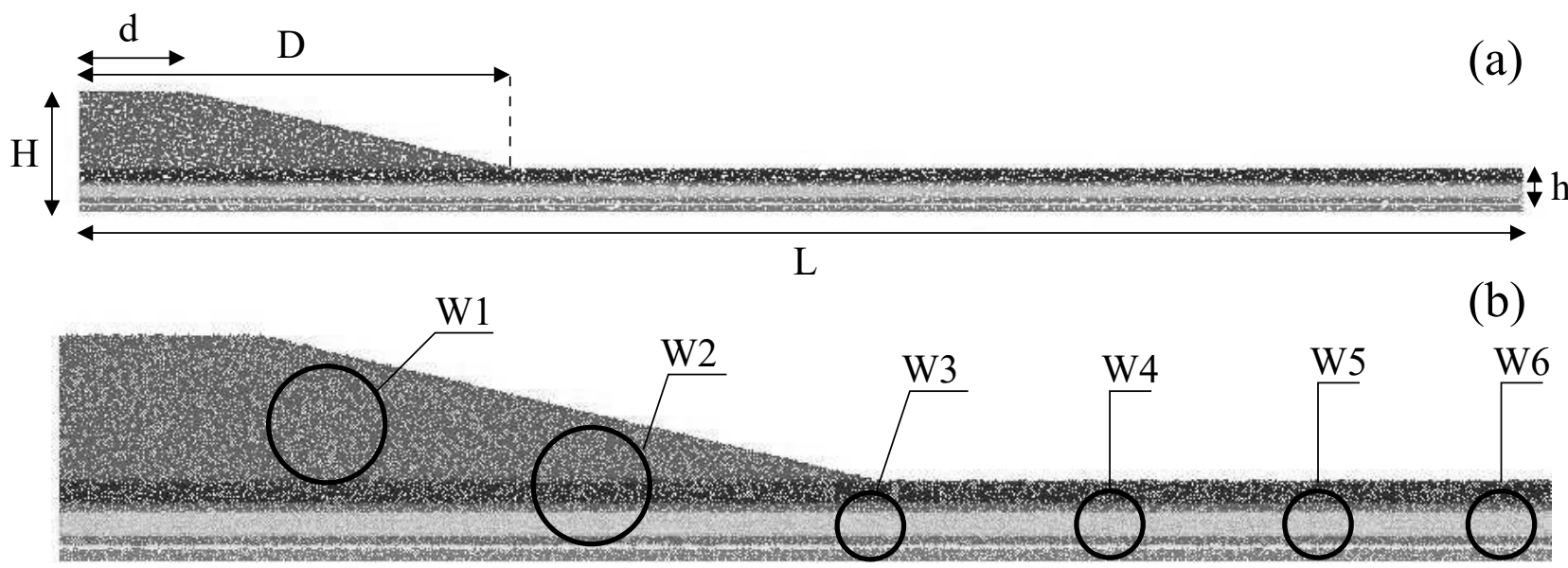

Figure 5. (a) Initial state of the sample used for forced-fold evolution, (b) definition of the different cells used for the structure analysis during the whole process 
A constant velocity equal to $0.5 \mathrm{~m} . \mathrm{s}^{-1}$ is imposed on the left wall during the whole process. The contact law is a frictional contact law $(\mu=0.4)$ with inelastic quasi-shocks (Jean, 1999) and each layer has the same mechanical properties. Due to the fact that in analogue sandbox, the cohesion between particles is avoided, for this first study, the cohesion is not considered in the numerical model. The simulation is decomposed in 20000 time steps of $2.510^{-2} \mathrm{~s}$. For the NSGS algorithm, a minimal number of iterations equal to 100 is imposed to ensure the quality of the solution (Renouf, 2004). To analyze the evolution of the structure, six cells are defined and tracked during the simulation process (Figure $5 \mathrm{~b}$ ). The characteristics of each cell (initial centre position and radius) are: $\mathrm{W} 1=(100,45,20), \mathrm{W} 2=(200,25,20)$, $\mathrm{W} 3=(300,15,12), \mathrm{W} 4=(400,15,12), \mathrm{W} 5=(500,15,12)$ and $\mathrm{W} 6=(600,15,12)$. Then for a given set all inside particles are tracked to observe the set deformation.

\subsubsection{Fold observations}

The sample is decomposed arbitrarily in layers of different height to analyse what kind of fold and internal geological structures can be observed during the simulation process. The Figure 6a gives the nine reference layers in the initial configuration.

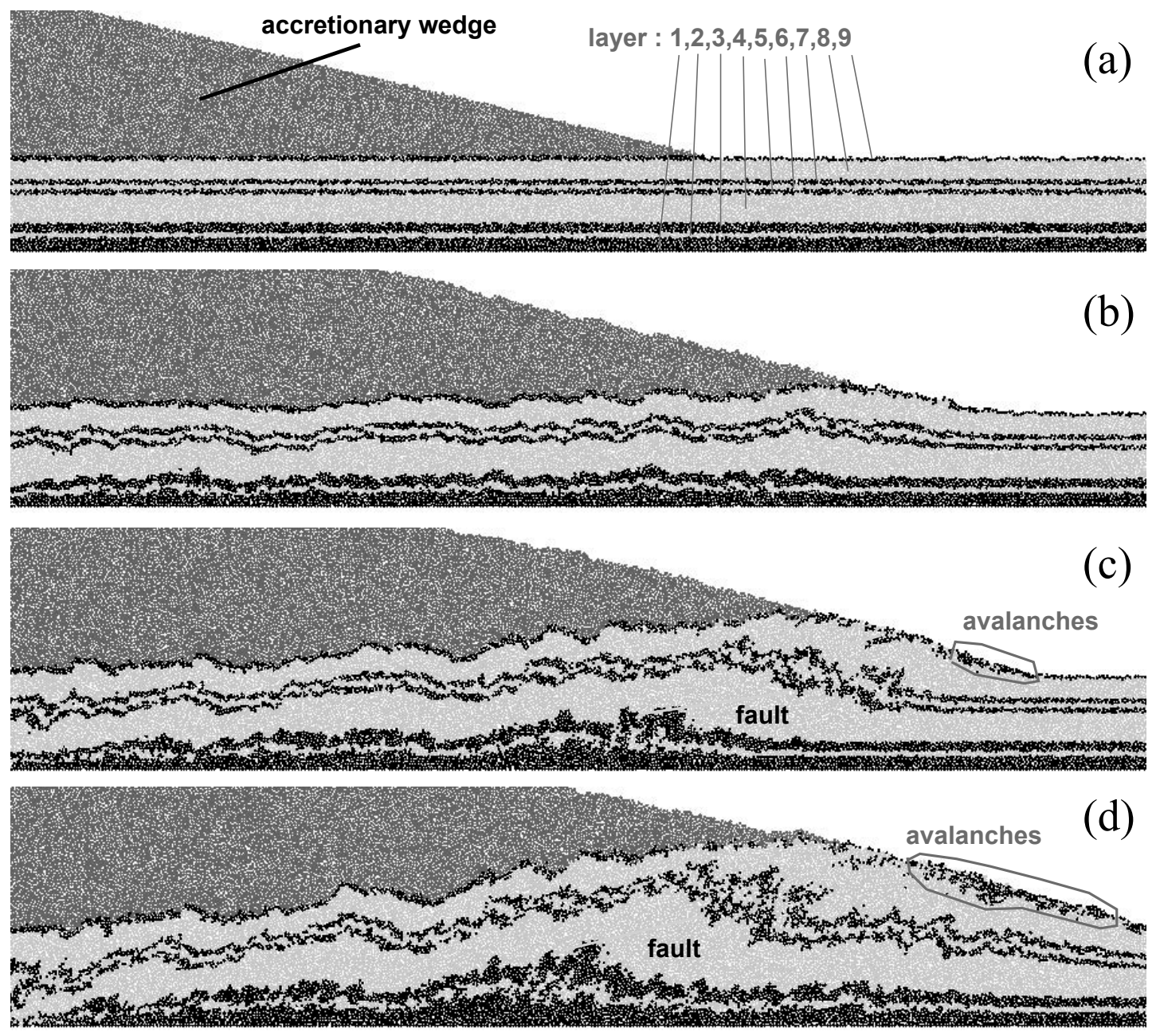

Figure 6. Different snapshots of the forced-fold evolution: (a) the initial configuration, (b) $t=200 \mathrm{~s}$, (c) $t=350 \mathrm{~s}$ and (d) the final state at $t=500 \mathrm{~s}$ 
An accretionary wedge is located on the left to reproduce the external structure used to constraint the evolution of the structure. In the Figure $6 \mathrm{~b}$ appear similar folds which correspond to folds with similar deformation (layers 5,6,7 for example). This formation is due to a vertical propagation of deformation initiated by the deformation of the first layer. This last one is submitted to hard constraints: the contact with the rigid plan, the force generated by the whole structure and the constant velocity imposed by the lateral wall. The force exerted by the accretionary wedge minimises the amplitude of deformations such buckling which occur during the process and are transmitted to the upper layers. On the front, the force decreases and larger deformations occur.

The Figure $6 \mathrm{c}$ shows the formation of a fault near the front of the wedge. The fault initiates a shear band clearly visible on the layer 3 for example. Consequently, the deformation of the first layer is not extended in the abscissa direction. The Figure 7 represents the evolution of the wedge front compared with the evolution of the lateral wall.

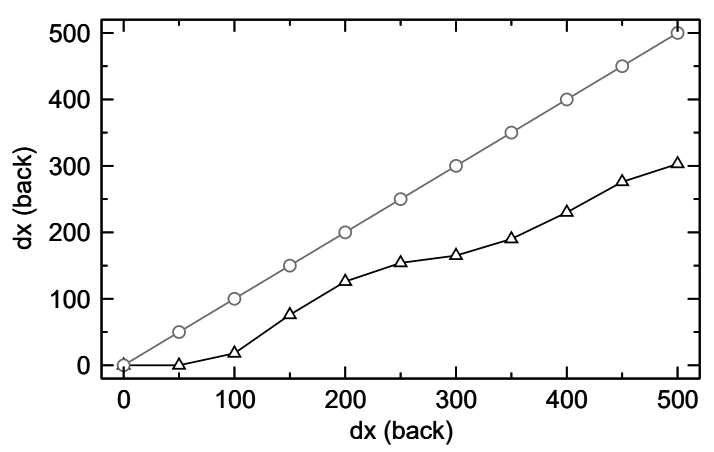

Figure 7. Evolution of the front of the accretionary wedge as a function of the evolution of the rear (black curve)

Its evolution does not match with the linear one (red line). It is due to the plastic deformation of the wedge and to internal faults and avalanches generated by the structure evolution. Faults generate vertical motions with few incidence on the evolution of the front while avalanches affect the position of the front in the abscissa direction. Before the fault, similar folds are always present but their orientation changes to match the internal fault direction. In the heads of the wedge, high deformations occur. Different faults and located avalanches appear but the mixing of different layers yields to a difficult analysis. The composition of the whole free surface changes. It is characterised by surface flows and the emergence of lower layers generated by the internal fault.

This last observation is verified in the Figure $6 \mathrm{~d}$. As the angle of the free surface increases avalanches occur (layer 9). Similar folds are concentrated under the left part of the wedge where vertical deformations are constrained. On the front of the wedge, after the fault localisation, the deformation of the first layers starts. It generates similar folds as the ones observed in the Figure $6 \mathrm{~b}$. The shear band created by the fault is not 
sufficient to support the whole deformation. Then the fault region starts to move with the evolution of the lateral wall and initiated deformations on its right.

\subsubsection{Mechanical analysis}

To complete fold observations, a short mechanical analysis is proposed through the evolution of the pressure and the deviatoric stress. The evolution of both quantities is represented in the Figure 9. The evolution of different cel, located in the Figure 5, is represented starting from their initial configuration given in the column (a) of the Figure 8. During the process, the stress tensor of a cell is computed from particles initially located in the corresponding cell. Consequently, as it can be observed in the Figure 8, there is no reason for the shape of the cell to stay circular.

(a)

(b)

(c)

(d)

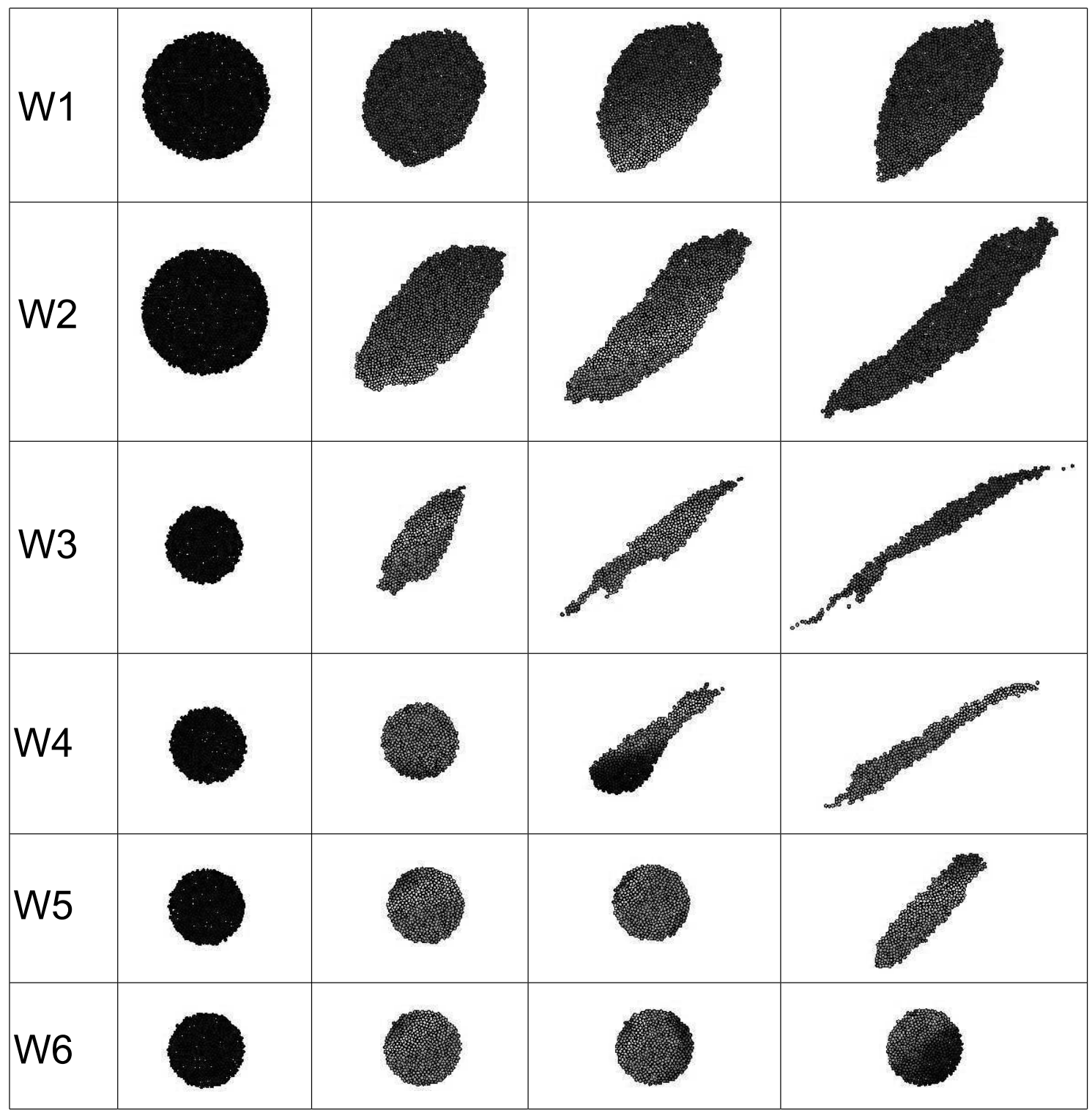

Figure 8. Shape evolution of the different cells defined in the Figure 5: (a) initial time, (b) $t=200 \mathrm{~s}$, (c) $t=350$ and (d) final time $t=500 \mathrm{~s}$ 
In addition to the stress evolution in the Figure 9, the length variations along the $\mathrm{X}$-axis and Y-axis are plotted in the Figure 10. It is then possible to obtain a kind of stress-strain relation quantifying the geometric informations on the shape evolution of the cells in the Figure 8.
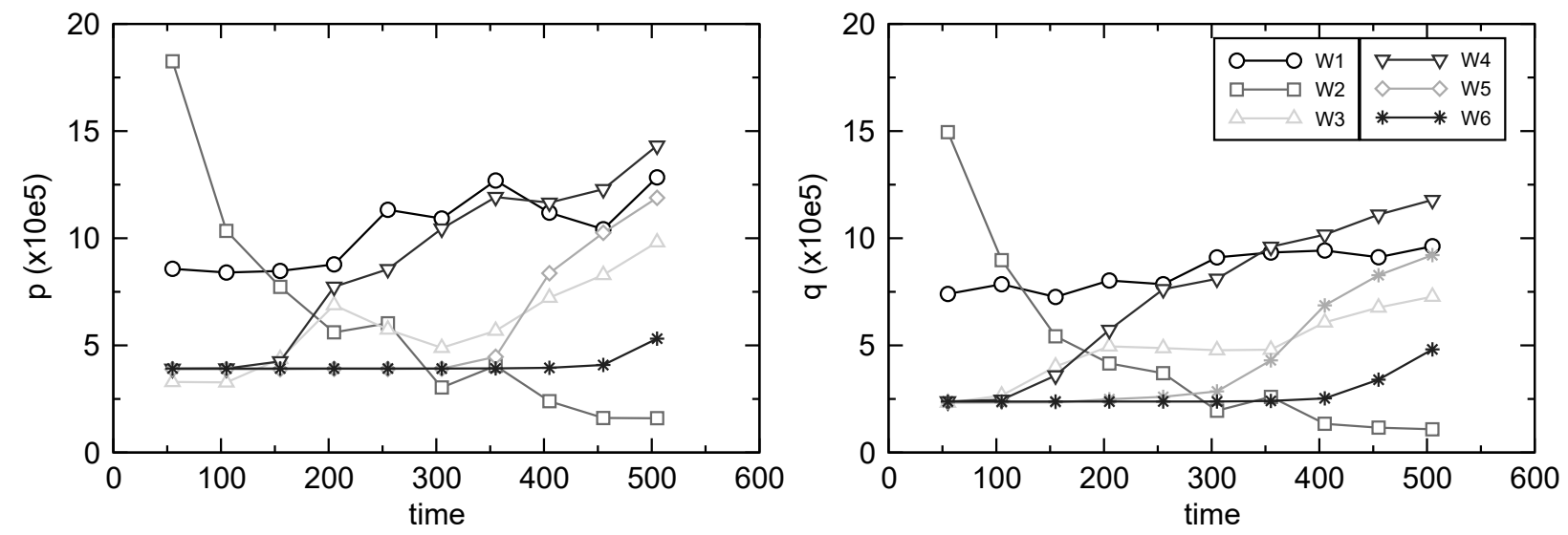

Figure 9. Evolution of the pressure and the deviatoric stress for the different sets of particles presented in the Figure 5
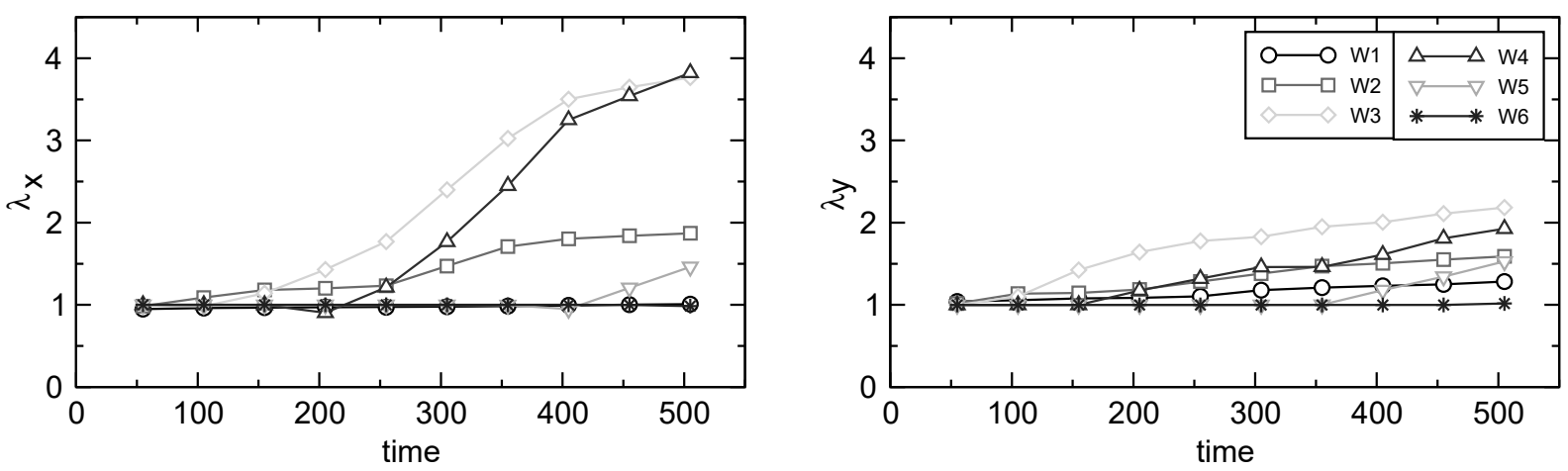

Figure 10. Evolution of $\lambda_{x}$ and $\lambda_{y}$ for the different set of particles presented in the Figure 5

Inside the accretionary wedge (W1), the pressure and the deviatoric stress have low variations. Since the wedge is not submitted to large deformations, the stress exerted on (W1) increases slowly. The increase is due both to the deformation of the interface between the wedge and the layer 9 and the pressure exerted by the lateral wall and the gravity. Contrary to cell (W1), the stress of the cell (W2) decreases during the whole process while its deformation increases and reaches a factor two along the abscissa direction. The cell (W3) and next cells are smaller than the first ones. As they are located in the lower part of the sample, parameters of the cell have been chosen to avoid both wall and surface effects. The front of the accretionary wedge appears as the most stressed region according to the deformation of (W3) and (W4) and the evolution of the pressure and the deviatoric stress in both cells. Both cells are submitted to large hydrostatic pressures and high shears which induce large dilatations along the axis. During the first half process the efforts exerted on the last cell (W5) are constant. 
The cell stays out of the influence of the wedge. When (W5) enter in the influence of the wedge, pressure and deviatoric stress start to grow and reach values equal to the one of (W1). The deformations have a small delay with the constraints. The cell supports the efforts during a short time interval before deformations occur. The efforts exerted on the last cell (W6) are constant. This last one is not really concerned by the displacement of the accretionary wedge.

\subsection{Fault propagations}

\subsubsection{Simulation parameter}

The sample used for the simulation of fault propagation is composed of 15000 hard cylinders. Their radius range from 0.13 to $0.26 \mathrm{~m}$. Their density is equal to $2800 \mathrm{~kg} \cdot \mathrm{m}^{-3}$. The characteristic length (in meter) of the sample presented in the Figure 11 are: $D=300, h=30$ and $\theta=30^{\circ}$. The lower plate of the sample is composed of two block. The first one is fixed and the second one has a constant velocity $V^{0}$ equal to $0.325 \mathrm{~m} . \mathrm{s}^{-1}$ in the fault direction e during the whole process. The contact law is a cohesive frictional contact law $(\mu=0.4)$ with inelastic quasishocks and as in the fold simulation, each layer has the same mechanical properties. The value of $\gamma$ range from $0 \mathrm{~N}$ (cohesionless) to $10^{5} \mathrm{~N}$. Values of $\gamma$ have been chosen according to the gravity force on a particle. The simulation is decomposed in 4000 time step of $110^{-2} \mathrm{~s}$. Precautionary measures for the NSGS algorithm are equivalent to the ones used for fold simulation.

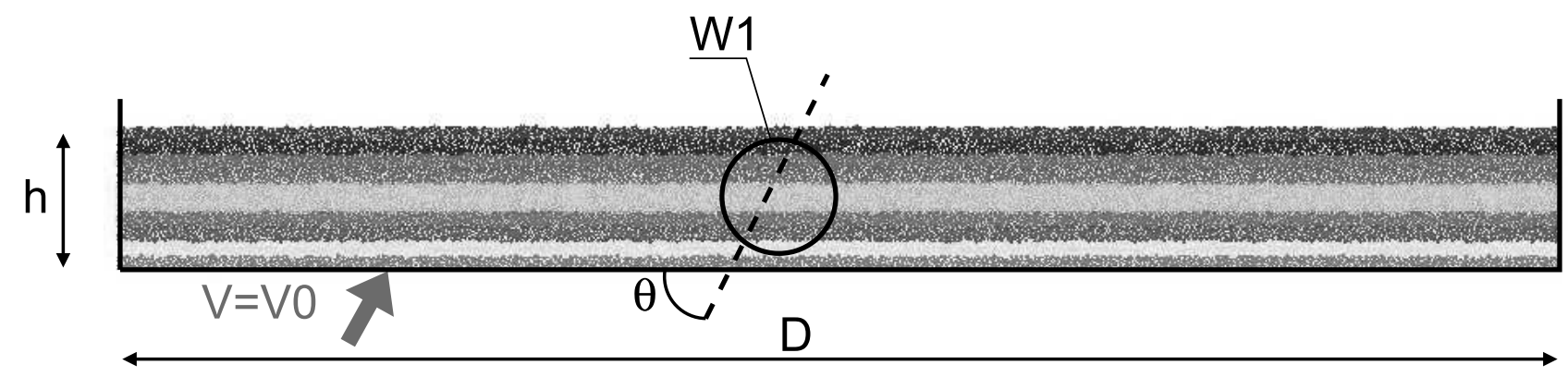

Figure 11. Initial state of the sample used for fault-propagation

A circular cells is defined and tracked during the simulation process (Figure 11). Its characteristics are $\mathrm{W} 1=(85,7.5,6)$ respectively its centre $(\mathrm{x}, \mathrm{y})$ and its radius.

\subsubsection{Internal cohesion effects}

The influence of the internal cohesion $\gamma$ on the profiles of both free surface and layers is studied. Four simulations have been performed for different values of $\gamma$ : (a) $0 \mathrm{~N}$, (b) $10^{3} \mathrm{~N}$, (c) $10^{4} \mathrm{~N}$ and (d) $10^{5} \mathrm{~N}$. The final profile of each simulation is represented in the Figures 12 and 13 which represents respectively the layer deformations 
and the velocity field. The front of the free surface is represented by the arrow, the fault direction by a continuous line, the left and right limits by dashed lines. The left limit separates the structure governed by a rigid motion from the other part. The right limit separates the undeformed structure from the other part. A fault area is then defined between the two limits as developed in the trishear model.

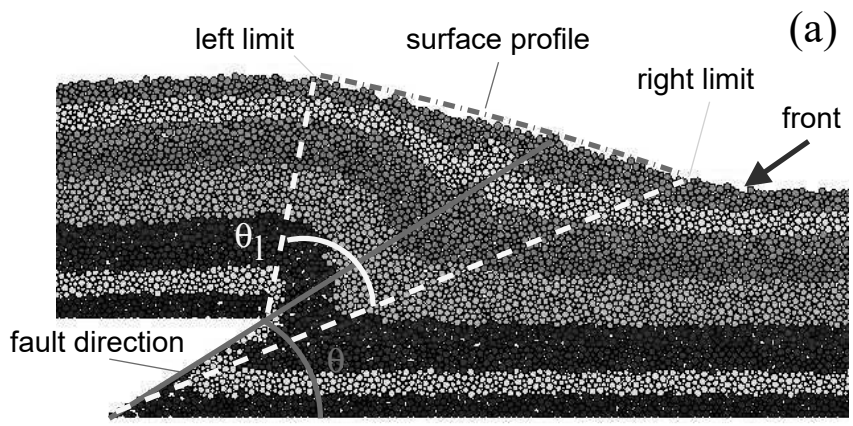

(a)

(c)
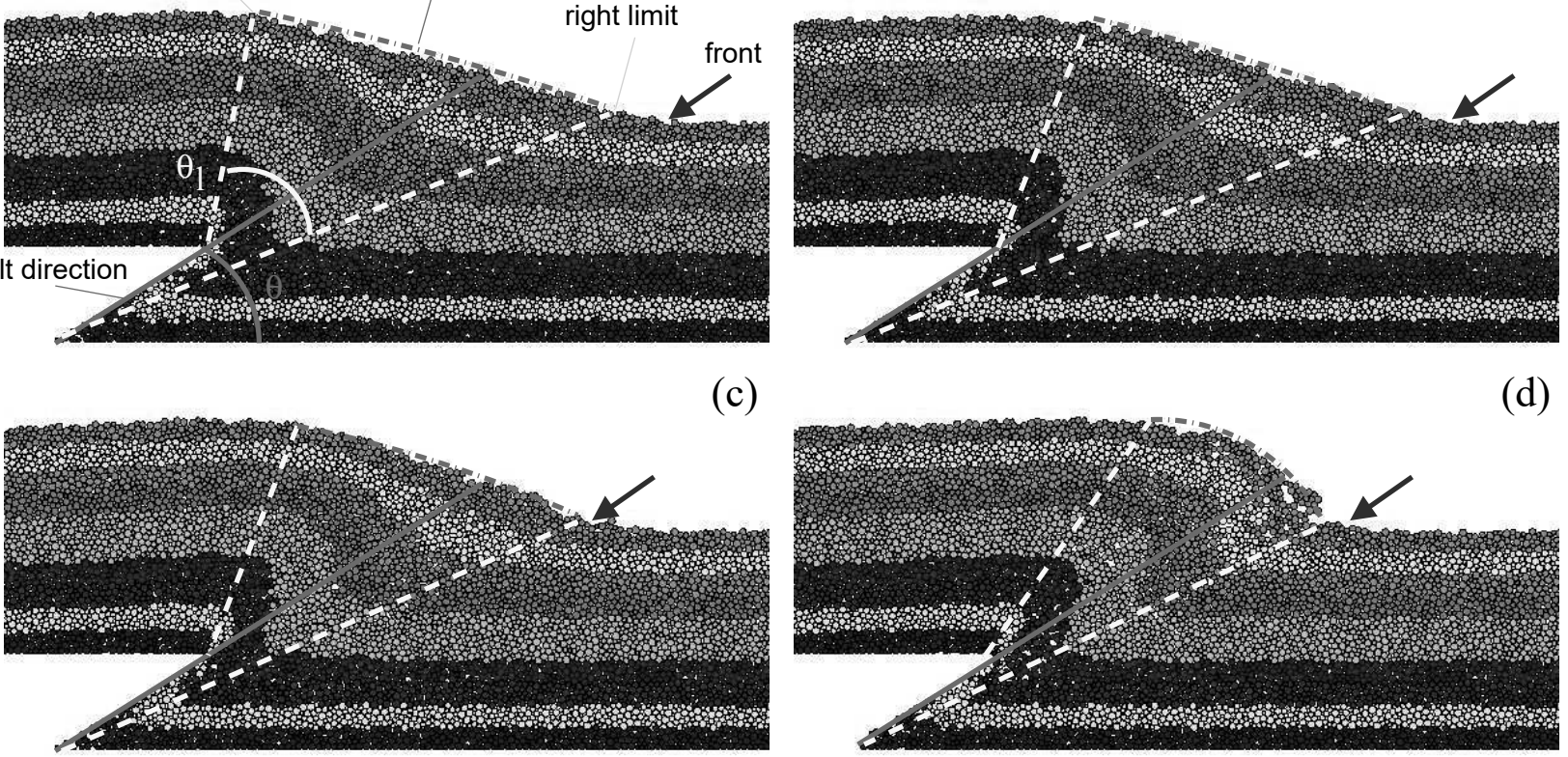

Figure 12. Free surface profiles for different values of $\gamma$ : (a) $0 \mathrm{~N}$, (b) $10^{3} \mathrm{~N}$, (c) $10^{4} \mathrm{~N}$ and (d) $10^{5} \mathrm{~N}$

Different aspects are related to the value of $\gamma$. The first one is the front of the free surface. With small values of $\gamma$, the fault propagation generates surface flows on long distance. When $\gamma$ increases, the region of surface flow propagation decreases. For the larger value of $\gamma$, the flows do not occur and are replaced by the detachment of blocks composed of several particles. To summarise, the distance between the front and the fault decreases when $\gamma$ increases. The second aspect is the left and right limit orientation which can be reduced to the angle $\theta_{l}$ (Figure 12a). The angle, initially larger than $\theta$, decreases when when $\gamma$ increases to become smaller than $\theta$ for the higher value of $\gamma$. The layer deformation is reduced for cohesive sample and the deformation fault is concentrated near its core. Moreover the Figure 12d underlines the fragility of the structure for strong internal cohesion. The last aspect concerns the free surface slope. For small values of $\gamma$ its radius is infinite (Figures 12a and 12b) and when $\gamma$ increases the radius decreases.

In complement of an analysis of the geometric deformation of the structure, a superposition of the velocity field is done (Figure 13). All reference marks defined previously stay unchanged. The good approximation of the trishear model is clearly underlined, especially for the cohesionless case. For each case of the Figure 13, the trishear model defined in the Figure 4 corresponds to an area. Nevertheless, two points must be highlighted. First, the surface area depends strongly on the internal cohesion. 
(a)
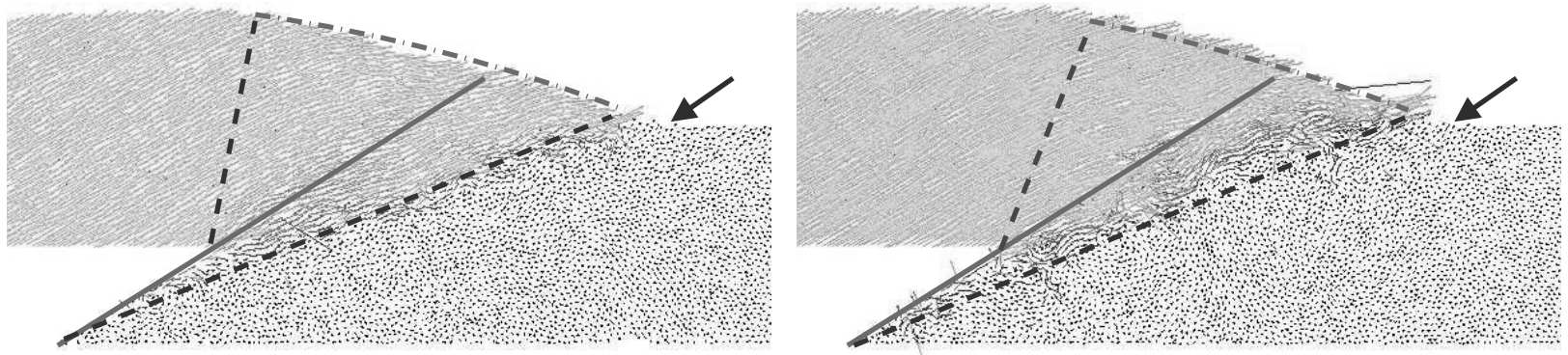

(c)

(d)
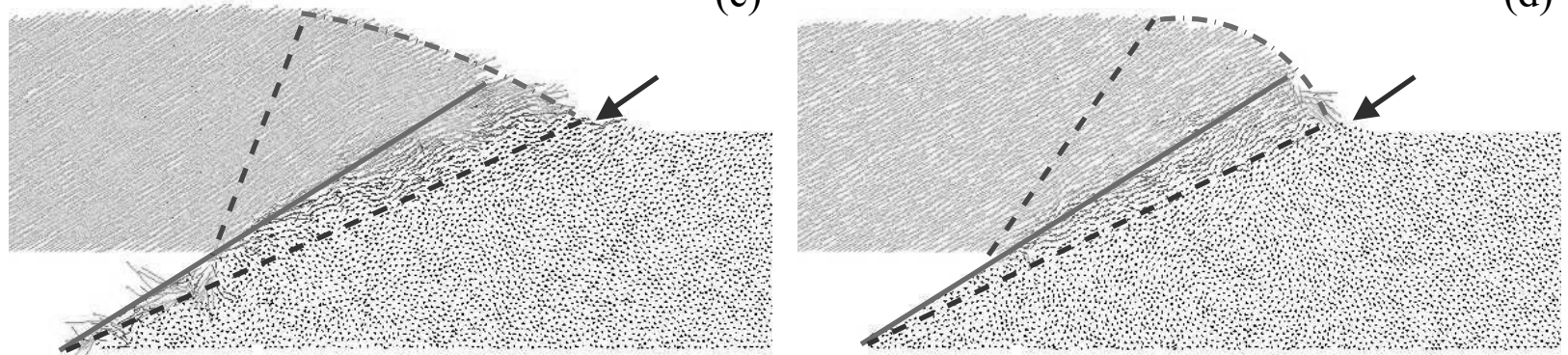

Figure 13. Velocity fields for different values of $\gamma$ : (a) $0 \mathrm{~N}$, (b) $10^{3} \mathrm{~N}$, (c) $10^{4} \mathrm{~N}$ and (d) $10^{5} \mathrm{~N}$

It decreases when $\gamma$ increases. Secondly, if the continuity of velocity fields seems correct for cohesionless simulations, when $\gamma$ do not vanishes, the continuity imposed by the model is no more observed. Internal cohesion and fault propagation generate shear between particles assemblies inside the fault area. Consequently, for cohesive sample, the continuity condition can not be conserved.

\subsubsection{Stress and strain analysis}

For the different values of $\gamma$, the pressure and the deviatoric stress in the cell W1 are tracked (Figure 14) as well as the evolution of $\lambda_{x}$ and $\lambda_{y}$ (Figure 15).
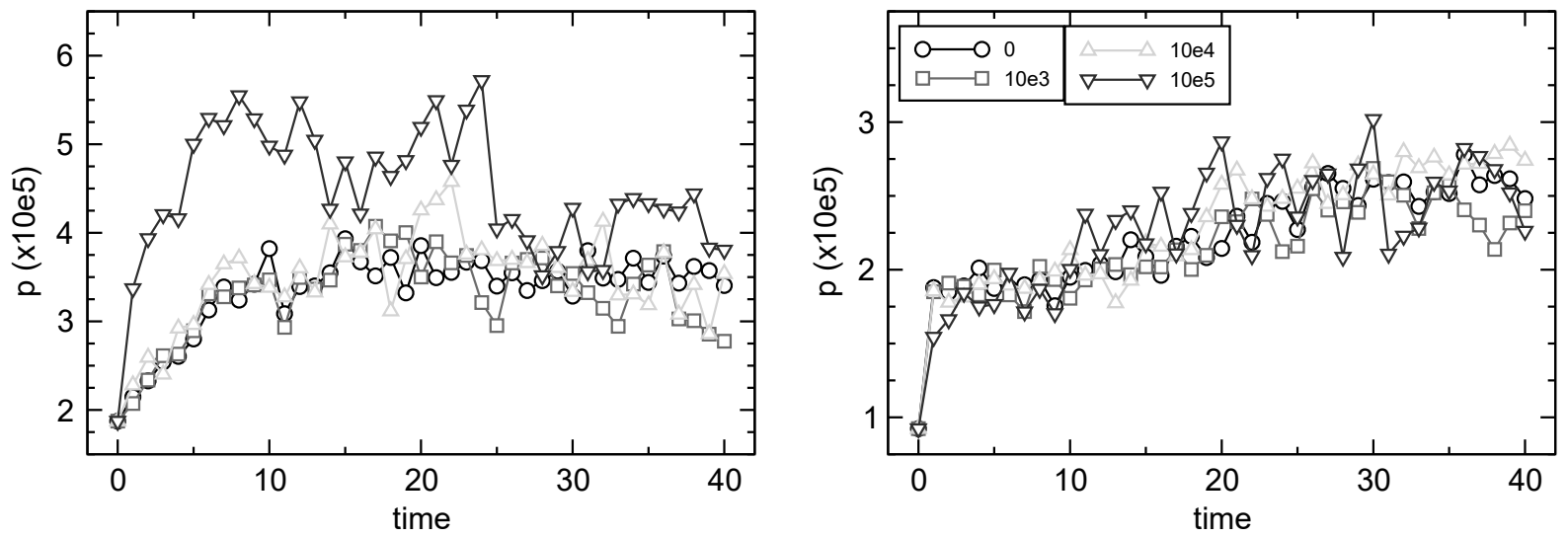

Figure 14. Evolution of the pressure and the deviatoric stress in the cell W1 for different values of $\gamma$ 
For each case, both pressure and deviatoric stress have a similar evolution due to the fact that the fault is controlled by a constant velocity. Their evolution seems decomposed in two phases. The first phase corresponds to the interval of time $[0,10]$. During this period, the pressure increases quickly whereas the deviatoric stress stays constant. Then on the time interval of time $[10,40]$, the pressure has a constant evolution while the deviatoric stress increases slowly. Note that the amount of pressure is similar, except for the highest value of $\gamma$ for which the pressure is twice as high. For this last ones, the second time interval is decomposed in two phases where the evolution of the pressure is constant for each phase.
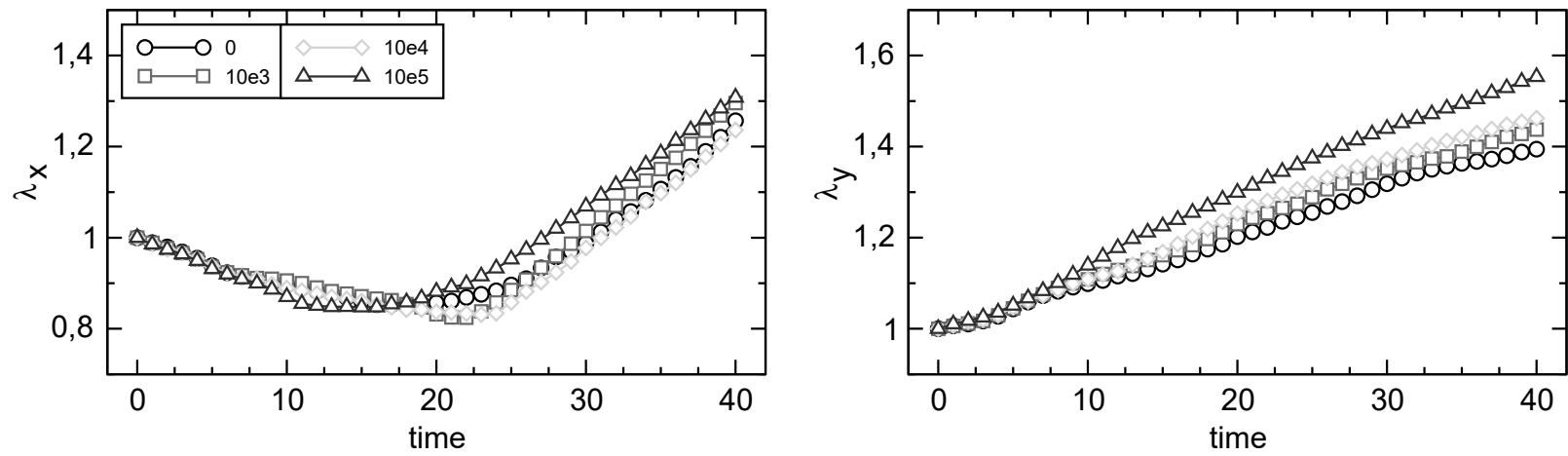

Figure 15. Evolution of $\lambda_{x}$ and $\lambda_{y}$ for cell $W 1$ and different values of $\gamma$

The evolution of deformations observed in the Figure 15 corresponds to the deformation near the fault. As stress components, their evolution can be decomposed in two phases. During the first phase corresponds, for each case $\lambda_{y}$ has the same evolution (a slow increase). Then $\lambda_{y}$ continue to increase but with different gradient (high for high value of $\gamma$ ). It is more difficult to decompose the evolution of $\lambda_{x}$ in two phases defined previously. Its evolution is clearly in two phases. During the first one, $\lambda_{x}$ decreases which corresponds to a compression exerted by the fault-propagation. During the second one, $\lambda_{x}$ increases which corresponds to the shear initiation inside the cell to reach the final state of the simulation represented in the Figure 16. This last figure illustrated the viscosity aspect induced by the cohesion.
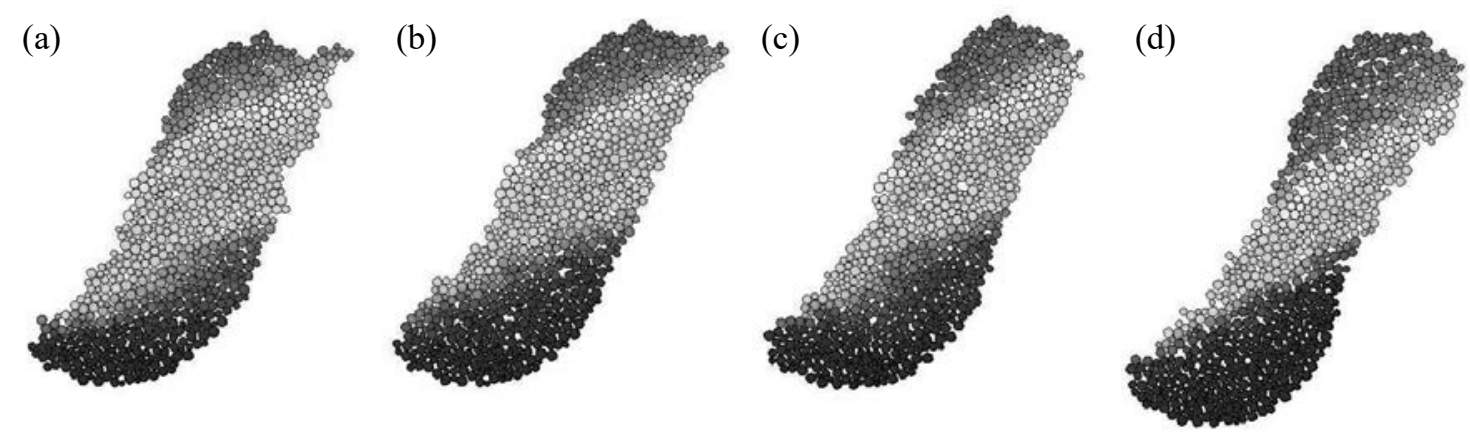

Figure 16. Final deformation state of the cell (W1) for different values of $\gamma$ : (a) $0 \mathrm{~N}$, (b) $10^{3} \mathrm{~N}$, (c) $10^{4} \mathrm{~N}$ and (d) $10^{5} \mathrm{~N}$ 


\section{Ending discussion}

There is a good agreement between geophysical observation and the mechanical analysis. For the forced-fold evolution, the internal stresses and the deformation have a good correlation with the numerical geological structures. The case of the internal fault is the more relevant. The time of it formation correspond to the high pressure and high shear exerted on the cells (W3) and (W4). Consequently the cells are crushed in a direction orthogonal to the shear motion generated by the fault. As a perspective of these first observations, it should be interesting to determine in further studies, mechanical models correlated to the formation of geological structures. For fault propagation, the influence of the internal cohesion has been strongly underlined by geometric, kinematic and mechanical aspects. It is interesting to see that the trishear model is the more relevant for cohesionless simulation. With a complete parametric study (angle of propagation, high of the sample), it seems possible to determine an extension to the model which takes into account the internal cohesion.

Although, evolution of mechanical properties agree with geophysical observations (fault and fold formations can be related to the deviatoric stress and the pressure exerted in the media), the notion of deformation in this kind of structure is not so clear. During large displacement, mixing induced by fold, fault and avalanches do not match with a continuous description of the media. Thus the choice of DEM is justified. The outstanding question is: is it necessary to represent the whole media as discontinuous when phenomena are local?. If an answer exist, it depends strongly on the study itself. Nevertheless combined approach should be a good solution to face this kind of problem but to be efficient the combination should be evolutive during the simulation process to switch from a continuous model to a discontinuous one.

\section{Acknowledgements}

Authors want to thank Alfredo Taboada, for geophysical discussions and its discrete element pre-processor. All Simulations have been performed with LMGC90 (http://www.lmgc.univ-montp2.fr/-dubois/LMGC90). This work is supported by the Centre Informatique National de l'enseignement Supérieur (CINES) under projects mgc2547 and $1 \mathrm{mc} 2644$.

\section{References}

Alart P., Curnier A., " A mixed formulation for frictional contact problems prone to Newton like solution method", Comput. Methods Appl. Mech. Engrg., vol. 92, n 3, 1991, p. 353-375.

Allen M., Tildesley D., Computer simulation of liquids, Oxford University Press, 1987.

Baraff D., " Issues in computing contact forces for non penetrating rigid bodies", Algorithmica, vol. 10, 1993, p. 292-352. 
Belytschko T., Organ D., Gerlach C., " Element-free galerkin methods for dynamic fracture in concrete”, Comput. Methods Appl. Mech. Engrg., vol. 187, n 3-4, 2000, p. 385-399.

Burbidge D., Braun J., “ Numerical models of the evolution of accretionary wedges and foldand-thrust belts using the distinct-element method", Geophys. J. Int., vol. 148, 2002, p. $542-561$.

Cardozo N., Bhalla K., Zehnder A., Allmendinger R., " Mechanical models of fault propagation folds and comparison to the trishear kinematic model", J. Struct. Geol., vol. 25, 2003, p. 1-18.

Chang K.-J., Taboada A., Chan Y.-C., “ Geological and morphological study of the Jiufengershan landslide triggered by the Chi-Chi Taiwan earthquake", Geomorphology, vol. 71, $n^{\circ} 3-4,2005$, p. 293-309.

Cottle R. W., Pang J., Stone R. E., The linear complementarity problem, Academic Press, Inc., Boston, MA, 1992.

Cundall P. A., “ A computer model for simulating progressive large scale movements of blocky rock systems", Proceedings of the symposium of the international society of rock mechanics, vol. 1, 1971, p. 132-150.

Cundall P. A., Strack O. D. L., “ A discrete numerical model for granular assemblies”, Geotechnique, vol. 29, $\mathrm{n}^{\circ} 1,1979$, p. 47-65.

de Saxcé G., Feng Z., "New inequation and functional for contact with friction”, J. Mech. of Struct. and Mach., vol. 19, 1991, p. 301-325.

Exadaktylos G. E., Vardoulakis I., Stavropoulou M. C., Tsombosc P., “ Analogue and numerical modeling of normal fault patterns produced due to slip along a detachment zone", Tectonophysics, vol. 376, 2003 p. 117-134.

Fillot N., Iordanoff I., Berthier Y., " Simulation of wear through a mass balance in a dry contact", ASME J. Tribol., vol. 127, n 1, 2005, p. 230-237.

Finch E., Hardy S., Gawthorpe R., " Discrete element modelling of contractional faultpropagation folding above rigid basement fault blocks", J. Struct. Geol., vol. 25, 2003, p. 515-528.

Hardy S., Finch E., “ Discrete Element modelling of the influence of cover strength on basement-involved fault-propagation folding”, Tectonophysics, vol. 415, 2006, p. 225-238.

Hardy S., McClay K., “ Kinematic modelling of extensional fault-propagation folding”, J. Struct. Geol., vol. 21, 1999, p. 695-702.

Hubbert M., " Mechanical basis for certain familiar geological structures”, Bull. Geol. Soc. America, vol. 62, 1951, p. 335-372.

Iordanoff I., Sève B., Berthier Y., “ Solid Third Body Analysis Using a Discrete Approach: Influence of Adhesion and Particle Size on the Macroscopic Behavior of the Contact", ASME J. Tribol., vol. 124, 2002, p. 530-538.

Jean M., “ The Non Smooth Contact Dynamics Method”, Compt. Methods Appl. Math. Engrg., vol. 177,1999 , p. 235-257.

Jean M., Acary V., Monerie Y., “ Non-smooth contact dynamics approach of cohesive materials", Phil. Trans. R. Soc. Lond. A, vol. 359, 2001 p. 2497-2518.

Kishino Y., " Disk Model Analysis of Granular Media”, Micromecanics of Granular Materials, 1988, p. 143-152. (eds. M. Satake and J.T. Jenkins), Elsevier. 
Kishino Y., Akaizawa H., Kaneko K., “ On the plastic flow of granular materials”, Y. Kishino (ed.), Powder and grains, 2001, p. 199-202.

Lanier J., Jean M., “ Experiments and numerical simulations with 2D disks assembly”, Powd. Tech., vol. 109, 2000, p. 206-221.

Lohrmann J., Kukowski N., Adam J., Oncken O., “ The impact of analogue material properties on the geometry, kinematics, and dynamics of convergent sand wedges", Journal of Structural Geology, vol. 25, 2003, p. 1691-1711.

Moreau J. J., “ Unilateral contact and dry friction in finite freedom dynamics”, J. Moreau, P.D. Panagiotopoulos (eds), Non Smooth Mechanics and Applications, CISM Courses and Lectures, vol. 302 (Springer-Verlag, Wien, New York), 1988, p. 1-82.

Pfeiffer F., Glocker C., Multibody dynamics with unilateral contacts, Non-linear Dynamics, John Wiley and Sons, 1996.

Renouf M., Optimisation Numérique et Calcul Parallèle pour l'étude de milieu divisés biet tridimensionnels, PhD Thesis, Université Montpellier II, Sciences et Technologie du Languedoc, September, 2004.

Renouf M., Acary V., Dumont G., " Comparison of Algorithms for collisions, contact and friction in view of Real-time applications", Multibody Dynamics 2005 proceedings, International Conference on Advances in Computational Multibody, Madrid, 21-24 June 2005.

Renouf M., Alart P., “ Conjugate gradient type algorithms for frictional multicontact problems: applications to granular materials", Comput. Methods Appl. Mech. Engrg., vol. 194, $\mathrm{n}^{\circ}$ 18-20, 2004, p. 2019-2041.

Renouf M., Bonamy D., Dubois F., Alart P., “ Numerical simulation of two-dimensional steady granular flows in rotating drum: On surface flow rheology", Phys. Fluids, vol. 17, 2005, p. 103303.

Renouf M., Dubois F., Alart P., " A parallel version of the Non Smooth Contact Dynamics Algorithm applied to the simulation of granular media", J. Comput. Appl. Math., vol. 168, 2004, p. 375-38, 2004.

Saussine G., Dubois F., Bohatier C., Cholet C., Gautier P., Moreau J., “ Modelling ballast behaviour under dynamic loading. Part 1: A 2D polygonal discrete element method approach", Comput. Methods Appl. Mech. Engrg., vol. 195, n 19-22, 2006, p. 2841-2859.

Taboada A., Chang K.-J., Radjaï F., Bouchette F., “ Rheology, force transmission, and shear instabilities in frictional granular media from biaxial numerical tests using the contact dynamics method", J. Geoph. Research, vol. 110, 2005, p. B09202.

Troadec H., Radjaï F., Roux S., Charmet J., “ Model for granular texture with steric exclusion”, Phys. Rev. E., vol. 66, 2002, p. 041305(4).

Yvonnet J., Chinesta F., Lorong P., Ryckelynck D., “ The constrained natural element method (C-NEM) for treating thermal models involving moving interfaces", Int. J. Therm. Sci., vol. $44, n^{\circ} 6,2005$, p. 559-569. 